\title{
If You Play in the Mud, You Get Dirty: The Appropriation of Amish Group Identity during a Negative Campaign ${ }^{1}$
}

\author{
Kyle C. Kopko \\ Adjunct Professor of Political Science \\ Elizabethtown College \\ kopkokyle@etown.edu \\ Steven M. Nolt \\ Professor of History and Anabaptist Studies \\ Young Center for Anabaptist and Pietist Studies \\ Elizabethtown College \\ nolts@etown.edu \\ Berwood A. Yost \\ Director, Center for Opinion Research \\ Franklin and Marshall College \\ berwood.yost@fandm.edu \\ Jackie Redman \\ Center for Opinion Research \\ Franklin and Marshall College \\ jackie.good@fandm.edu
}

\begin{abstract}
Using an original online experiment, we test whether the appropriation of Amish group identity influences voter behavior. We do not find that the appropriation of Amish group identity influences intended vote choice. However, there is evidence that associating the Amish with a candidate who was subjected to negative advertisements resulted in a reduction in approval rating for the Amish as a group. In addition, we find that the attitudes toward the Amish vary by respondent ideology and, consistent with the contact hypothesis, those individuals who interact regularly with the Amish reported more favorable ratings toward the Amish. The results raise important questions regarding the appropriation of a group's image in the course of a political campaign.
\end{abstract}

Submitted October 4, 2020; accepted December 15, 2020; published March 24, 2021

https://doi.org/10.18061/jpac.v1i2.7950

Keywords: Amish, voting, religion and politics, experiment, group identity, cultural appropriation, presidential election

\footnotetext{
${ }^{1}$ Portions of these findings were presented at a public lecture in the fall of 2018. Following the presentation, a member of the Old German Baptist Brethren Church approached the authors and summarized his understanding of the findings this way: "If you play in the mud, you get dirty." We acknowledge this anonymous audience member's observation with this title.
} 


\section{Introduction}

Amish. Politics. These words rarely go together. Since their arrival in North America in the mid1700s, Old Order Amish have largely refrained from voting and other forms of political participation due to their religious beliefs. The Amish and other conservative Anabaptists believe that political involvement is inconsistent with the teachings of Jesus Christ and compromises their separation from worldly society. ${ }^{2}$ As one Amish publication puts it, "If we don't want the government to tell us how to conduct our church affairs, we had better not tell them how to run the government" (1001 Questions, 1992, p. 157). In addition, some members of the Amish community believe that voting for federal officeholders - especially presidential candidates - conflicts with the Amish belief in peace and nonviolence. After all, the president serves as commander-in-chief of the armed forces (see Kraybill \& Kopko, 2007).

Nevertheless, in recent history, there have been efforts to mobilize this group of potential voters. Given the conservative Christian beliefs of Old Order Amish communities and their preference for a nonintrusive state, these individuals would likely support conservative and Republican candidates - if they go to the polls. In 2016, for the first time, a political action committee based in Arlington, Virginia, named Amish PAC, ${ }^{3}$ sought to mobilize members of the Amish community in key battleground states. With the assistance of a former member of the Amish church, Amish PAC spent $\$ 139,692.88$ between April and December of 2016 on administrative and outreach efforts. ${ }^{4}$ These expenditures supported direct meetings with members of the Amish community, billboard advertisements, advertisements in periodicals frequently read by the Amish, and the recruitment of non-Amish donors and volunteers to support the PAC's efforts. Amish PAC advertisements may have influenced non-Amish voters, and that is the subject of this analysis.

Figure 1 depicts a billboard advertisement that Amish PAC displayed in Amish communities throughout central Pennsylvania during the 2016 election. It features a picture of Donald Trump sitting at a desk, while an Amish horse and buggy travels down a country road with an "I voted" sticker prominently displayed on the back of the buggy. The implication is that Amish do or should support Donald Trump for president. While the target audience of this advertisement was the Amish community, these billboards were viewed by countless individuals traveling along highways in central Pennsylvania and could have affected non-Amish voters. The outreach efforts

\footnotetext{
${ }^{2}$ As Kopko (2012, p. 368) notes: "Anabaptists traditionally thought of church and state as two kingdomsthe Kingdom of God and the kingdom of man." Underscoring this notion, Amish place particular emphasis on Christ's assertion in John 18:36 (NRSV): "My kingdom is not of this world."

${ }^{3}$ See www.Amish PAC.com. Retrieved October 1, 2020. See Appendix A for supplemental information on the creation of Amish PAC.

${ }^{4}$ According to Federal Election Commission data, contributions came from donors in 41 states, constituting a significant outreach effort. See https://www.fec.gov/data/receipts/individual-contributions/?two year transaction period $=2016 \&$ committee $\mathrm{id}=\mathrm{C} 00615344 \& \min$ date $=04 \% 2 \mathrm{~F} 01 \% 2 \mathrm{~F} 2016 \& \max$ date $=12 \% 2 \mathrm{~F}$ 31\%2F2016. Accessed October 1, 2020.
} 
by Amish PAC provide an opportunity to test an important, yet understudied, phenomenon in campaigns and elections - appropriating the image of a social group for potential political gain.

\section{Figure 1}

Amish PAC Billboard Supporting Donald Trump, 2016

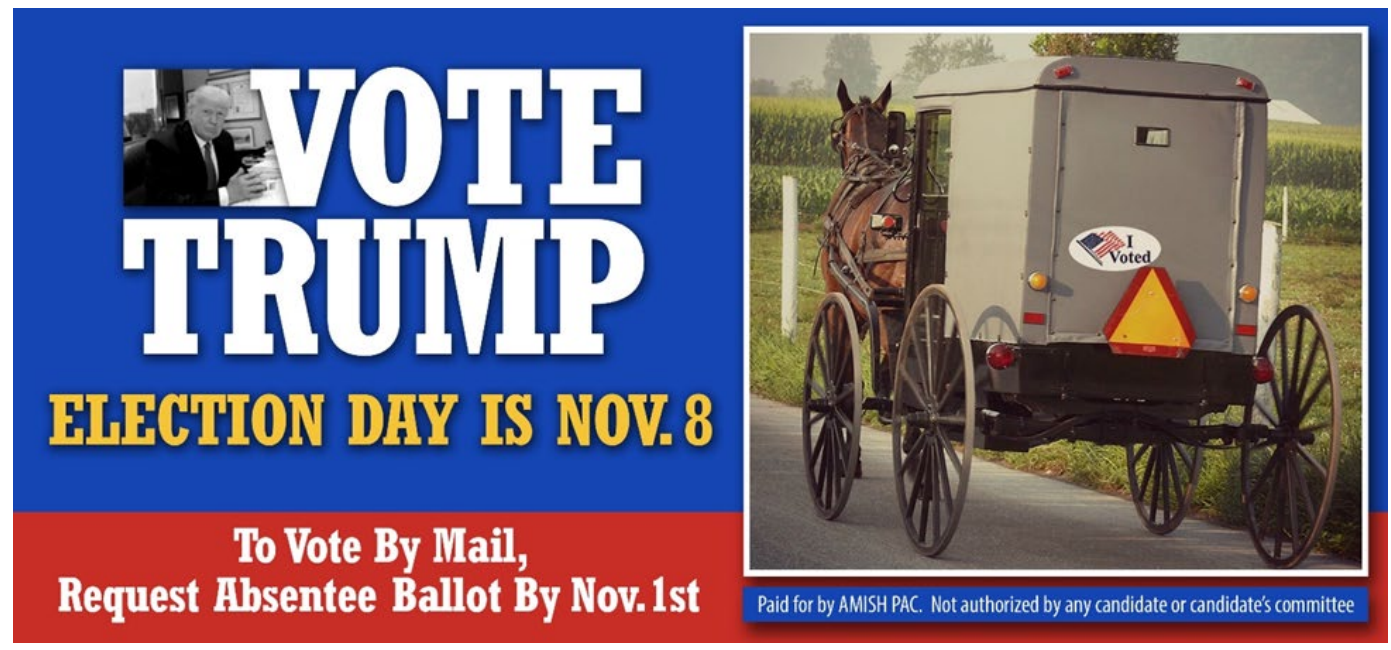

For generations, campaign signs, advertisements, and rallies have emphasized the linkage between a candidate and various coalition groups (e.g., veterans, teachers, coal miners, women, etc.). This tactic conveys symbolic support of a social group for a candidate and their policy positions. Political scientists have long studied how political language and action can be used as symbols to influence publics in various ways (e.g., Edelman, 1964). Furthermore, emotional appeals in political advertisements influence voter behavior (e.g., Brader, 2005). Thus, the symbolic use of a group's image, in what may be perceived as an emotional appeal, could influence political behavior.

But what is the effect of appropriating the image of the Amish in the course of a campaign, particularly on non-Amish individuals? During the twentieth century, popular images of the Amish shifted from one of hapless rubes sadly out of step with contemporary life to one of hardworking, trustworthy people preserving laudable values that others had abandoned (Weaver-Zercher, 2001). Not every media representation of the Amish is positive, but even negative news stories generally rest on a sense that the Amish in question are not living up to the high standards expected of them, thus reinforcing positive assumptions as part of an otherwise negative presentation. ${ }^{5}$

Trollinger (2012) and Weaver-Zercher (2013) have connected the evolution to Americans' desire to reclaim lost virtues through images of the Amish and other Plain Anabaptist groups. A positive public perception, in turn, transfers to things associated with the Amish. For example, when asked to compare Amish-made products with similar goods from another source, tourists to Lancaster County, Pennsylvania, overwhelmingly associated the Amish "brand" with value,

\footnotetext{
${ }^{5}$ See, for example, case studies in Umble and Weaver-Zercher (2008, pp. 43-87, pp. 133-153).
} 
artisanship, and quality (Kraybill \& Nolt, 2004, p. 195). Do the positive product perceptions associated with Amish baked goods, quilts, and furniture extend to political candidates, thus increasing a voter's likelihood of voting for a candidate linked to the Amish? And does the transference run the other way, saddling the Amish, for better or worse, with the image of the politician, and thereby influencing how individuals perceive the Amish?

It is plausible that the appropriation of the Amish image could influence both perceptions of the candidate (vis-à-vis intended vote choice) and perceptions of the Amish as a group (by associating the group with a politician). Goren and Chapp (2017) provide some justification for this potential relationship. They find that partisan predisposition and religious beliefs exert influence on "culture war" issues. The authors also find strong evidence that preferences on culture war issues influence partisan identity and religious orientations. If feelings toward the Amish could approximate culture war issues, then one might expect dual transference. Furthermore, it is welldocumented that political and partisan attachments can act as a "perceptual distortion" (Campbell et al., 1960, p. 133) and a heuristic (e.g., Rahn, 1993) that influences decision-making. Thus, attitudes toward the Amish may vary once this group is associated with a candidate.

Finally, do perceptions of the Amish vary based upon the respondent's ideology and level of contact with this group? It may be the case that self-identified political conservatives have more favorable attitudes toward the Amish since some conservatives may identify with the Amish community's perceived agrarian lifestyle and Christian beliefs. Additionally, consistent with the contact hypothesis (Allport, 1954), it should be the case that attitudinal bias toward a group decreases with repeated and meaningful interaction. Here, we should expect more favorable attitudes toward the Amish among respondents who regularly interact with them.

To test these research questions, we employ an online experimental survey that assesses the treatment effects of the Amish PAC billboard among voters in Lancaster County, Pennsylvania. However, we do not employ the billboard that features President Trump's image. We instead revised the advertisement and randomized treatments to include photos and language supporting Democratic and Republican nominees for governor in 2018-Tom Wolf and Scott Wagner, respectively. Ultimately, we find that the experimental manipulation (i.e., treatment) did not change the statistical likelihood that a voter would favor the treated or untreated candidate. While there is no evidence of the treatment influencing vote choice, there is evidence that associating the Amish with a particular political candidate results in a statistically distinguishable reduction in approval rating for the Amish as a group. As we discuss later, we attribute this finding to the negative depictions of Wagner in the course of the primary election by one of his challengers. In addition, we find the attitudes toward the Amish vary by respondent ideology and, consistent with the contact hypothesis, those individuals who interact regularly with the Amish reported more favorable ratings toward the Amish. The results raise important questions regarding the appropriation of a group's image, especially without its consent, in the course of a political campaign. 


\section{Methods}

\section{Experimental Design}

Subjects were randomly assigned to one of two conditions. Subjects in the first experimental group (Wagner Amish PAC) were shown a stock image of incumbent Governor Tom Wolf (D) and a second image of challenger Scott Wagner (R) that showed an endorsement by Amish PAC. Subjects in the second experimental group (Wolf Amish PAC) were shown a stock image of Scott Wagner and a second image of Tom Wolf that offered an endorsement by Amish PAC. See Figure 2.

\section{Figure 2}

\section{Experimental Manipulation of Amish PAC Advertisement}

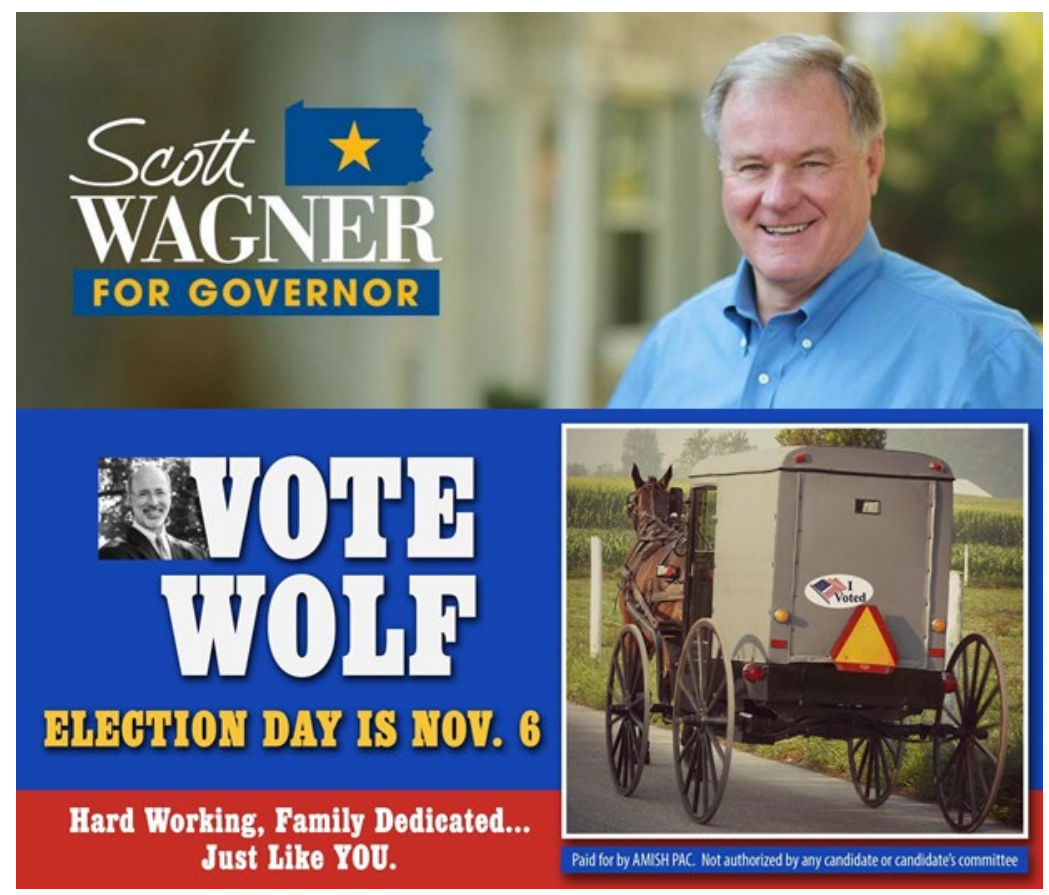

Respondents in both conditions were asked, "If the 2018 election for governor were being held today and the candidates included Tom Wolf, the Democrat, and Scott Wagner, the Republican, would you vote for Tom Wolf, Scott Wagner, some other candidate, or aren't you sure how you would vote?" Respondents in both conditions were also asked to use a feeling thermometer to rate each candidate and the Amish. ${ }^{6}$

The feeling thermometers for each candidate gave respondents these directions: "Please use the scale below from minus 100, meaning you would be extremely unhappy, to positive 100, meaning you would be extremely happy, to indicate how happy you would feel" if that candidate were elected governor. The feeling thermometer for the Amish was worded this way: "How do you feel about the Amish as a group? Please use the scale below from minus 100, meaning you

\footnotetext{
${ }^{6}$ For more information on feeling thermometers, see Nelson (2008).
} 
feel extremely unfavorable about the Amish as a group, to positive 100, meaning you feel extremely favorable about the Amish as a group, to indicate your level of favorability toward the Amish."

\section{Participants and Procedures}

The experiment was embedded in an online survey of registered voters residing in Lancaster County, Pennsylvania. In many ways, this is an ideal sample due to the presence of a large Amish population in Lancaster County. Some respondents will have had regular interaction with the Amish, while others will have had no interaction. This variability of exposure will be important for the analysis detailed later in this article.

The survey was approved by the Elizabethtown College Institutional Review Board. Interviewing took place after the 2018 primary election, from May 17 to June 26, 2018. The survey used a sample of registered voters obtained from L2, a list management company. All selected voters were mailed a postcard that described the survey, and follow-up telephone calls to encourage participation were also made. A total of 422 online surveys were completed. A total of 192 subjects were assigned to the Wagner Amish PAC group and 230 were assigned to the Wolf Amish PAC group. Table 1 shows the distribution of demographic and political variables by experimental condition. There is no significant difference between the experimental groups by gender, employment, age, education, religious affiliation, income, party affiliation, or past voting behaviors. There is a statistically significant difference between groups in political ideology. 
Table 1

Demographic and Political Variables by Experimental Condition

\begin{tabular}{|c|c|c|}
\hline & \multicolumn{2}{|c|}{ Experimental Condition } \\
\hline & Wagner Amish PAC & Wolf Amish PAC \\
\hline & $(n=192)$ & $(n=230)$ \\
\hline Years Living in Lancaster (mean (sd)) & $35.79(21.63)$ & $37.72(21.55)$ \\
\hline Male $(\%)$ & $103(54.5)$ & $130(58.8)$ \\
\hline \multicolumn{3}{|l|}{ Work Status (\%) } \\
\hline Fulltime & 89 (48.9) & $98(43.8)$ \\
\hline Other & $38(20.9)$ & $47(21.0)$ \\
\hline Retired & $55(30.2)$ & $79(35.3)$ \\
\hline \multicolumn{3}{|l|}{ Age Group (\%) } \\
\hline Under 35 & $29(15.1)$ & 19 (8.3) \\
\hline $35-54$ & $46(24.0)$ & $57(24.8)$ \\
\hline Over 55 & $117(60.9)$ & $154(67.0)$ \\
\hline \multicolumn{3}{|l|}{ Educational Attainment (\%) } \\
\hline College degree & $115(61.2)$ & $127(55.9)$ \\
\hline Some college & $47(25.0)$ & $58(25.6)$ \\
\hline HS or less & $26(13.8)$ & $42(18.5)$ \\
\hline \multicolumn{3}{|l|}{ Religious Affiliation (\%) } \\
\hline Catholic & $17(9.2)$ & $32(15.0)$ \\
\hline Other, unaffiliated & $68(37.0)$ & $71(33.3)$ \\
\hline Protestant & $99(53.8)$ & $110(51.6)$ \\
\hline \multicolumn{3}{|l|}{ Income (\%) } \\
\hline Under $\$ 35,000$ & $20(13.2)$ & $20(10.9)$ \\
\hline$\$ 35-75,000$ & $57(37.5)$ & $68(37.2)$ \\
\hline Over $\$ 75,000$ & $75(49.3)$ & $95(51.9)$ \\
\hline \multicolumn{3}{|l|}{ Ideology $(\%)^{*}$} \\
\hline Conservative & $60(32.4)$ & $96(44.4)$ \\
\hline Liberal & $47(25.4)$ & $52(24.1)$ \\
\hline Moderate & $78(42.2)$ & $68(31.5)$ \\
\hline \multicolumn{3}{|l|}{ Party Identification (\%) } \\
\hline Strong Republican & $44(24.0)$ & $59(26.9)$ \\
\hline Republican & $16(8.7)$ & $24(11.0)$ \\
\hline Lean Republican & $20(10.9)$ & $25(11.4)$ \\
\hline Independent & $15(8.2)$ & $12(5.5)$ \\
\hline Lean Democrat & $24(13.1)$ & $21(9.6)$ \\
\hline Democrat & $8(4.4)$ & $15(6.8)$ \\
\hline Strong Democrat & $53(29.0)$ & $60(27.4)$ \\
\hline Times voted in past 5 general elections (mean (sd)) & $3.37(1.40)$ & $3.36(1.37)$ \\
\hline Times voted in past 5 primary elections (mean (sd)) & $1.68(1.51)$ & $1.70(1.55)$ \\
\hline
\end{tabular}

Note. ${ }^{*}$ denotes a statistically significant difference at $p<.05$. 


\section{Results}

Table 2 shows vote preference and feeling thermometer ratings by experimental condition. The political variables show no differences by experimental group; that is, the Amish PAC endorsement does not appear to make any difference in respondents' gubernatorial preference or in their feelings about either candidate, but it does appear to affect feelings about the Amish. The unadjusted feeling thermometer ratings of the Amish were nearly nine points lower among respondents who received the Wagner Amish PAC treatment than they were for respondents who received the Wolf Amish PAC treatment.

Table 3 presents logistic regression coefficients for vote choice. The probability of preferring Tom Wolf for governor was not affected by association with the Amish PAC advertising, even after adjusting for Amish PAC ad awareness, gender, age, education, political ideology, and political party identification.

\section{Table 2}

Gubernatorial Preference and Feeling Thermometer Ratings by Experimental Condition

\begin{tabular}{lcr}
\hline & \multicolumn{2}{c}{ Experimental Condition } \\
\cline { 2 - 3 } & Wagner Amish PAC & Wolf Amish PAC \\
\cline { 2 - 3 } & \multicolumn{1}{c}{$(\mathrm{n}=192)$} & $(\mathrm{n}=230)$ \\
\hline Feeling Thermometer Tom Wolf (mean (sd)) & $23.24(80.63)$ & $16.88(83.56)$ \\
Feeling Thermometer Scott Wagner (mean (sd)) & $-6.19(83.63)$ & $-5.13(84.79)$ \\
Feeling Thermometer Amish (mean (sd)) & $59.63(45.74)^{*}$ & $68.31(39.89)^{*}$ \\
Gubernatorial Preference (\%) & & \\
Don't know & $30(15.6)$ & $35(15.2)$ \\
Other & $4(2.1)$ & $5(2.2)$ \\
Refused & $5(2.6)$ & $4(1.7)$ \\
Wagner & $65(33.9)$ & $88(38.3)$ \\
Wolf & $88(45.8)$ & $98(42.6)$ \\
\hline
\end{tabular}

Note. ${ }^{*}$ denotes a statistically significant difference at $p<.05$. 
Table 3

Logistic Regression Predicting Vote Choice

\begin{tabular}{lrr}
\hline Variable & Estimate & Std. Error \\
\hline (Intercept) & $3.079^{\wedge}$ & 1.629 \\
Experimental Condition Wolf Amish PAC & -0.123 & 0.662 \\
Recognized Amish PAC Sponsorship & $-2.071^{\wedge}$ & 1.095 \\
Male & 0.817 & 0.675 \\
Over 55 years of age & -0.594 & 0.659 \\
Under 35 years of age & -0.968 & 1.243 \\
No college degree & -0.208 & 0.618 \\
Liberal & 19.340 & 1732.065 \\
Moderate & $2.082^{* *}$ & 0.660 \\
Independent & $-4.438^{* *}$ & 1.426 \\
Republican & $-6.060^{* * *}$ & 1.198 \\
\hline N = 313 & & \\
Percent Correctly Classified $=95.8 \%$ & & \\
Model Sensitivity $=98.2 \%(165 / 168)$ & & \\
Model Specificity $=93.1 \%(135 / 145)$ & & \\
Null Deviance: 429.526 on 312 degrees of freedom & & \\
Residual Deviance: 81.769 on 302 degrees of freedom & & \\
AIC: 103.77 & & \\
\hline
\end{tabular}

Note. The logistic regression model predicted the probability of voting for Tom Wolf. Only respondents who expressed a preference for Wolf or Wagner were included in this analysis.

${ }^{\wedge}$ p. $<.10 .{ }^{*}$ p. $<.05 .{ }^{* *}$ p. $<.01 .{ }^{* * *}$ p. $<.001$.

Table 4 presents the least-squares regression coefficients for the Amish feeling thermometer score. The regression results show that feelings about the Amish are related to both political ideology and the interaction between ideology and personal exposure to the group. Liberals tend to rate the Amish lower than moderates or conservatives, but this relationship is specified by the amount of personal interaction the respondent has with the Amish. Figure 3 displays the interaction between ideology, personal exposure, and ratings. The coefficients also show that ratings of the Amish differ depending on which candidate was depicted as being supported by the Amish PAC. The adjusted ratings of the Amish were about eight points higher among respondents who received the Wolf Amish PAC treatment than for those who received the Wagner Amish PAC treatment $(\mathrm{p} .=.058)$. The model presented in Table 4 is a simplified model where the ideology variable classifies respondents as those who identify as liberal versus a combined category of self-identified moderates and conservatives. It also includes a binary measure of those who have contact with the Amish versus those who do not. The model in Table 4 excludes interaction terms. We report the simplified model here because it is easier to interpret. Appendix B provides a least-squares model that uses the full range of values for political ideology and personal exposure to the Amish. The 
results in Table B1 are consistent with the result produced in Table 4, where these indicators are dichotomized.

\section{Table 4}

Least-Squares Regression Predicting Feeling Towards Amish

\begin{tabular}{lrc}
\hline Variable & Estimate & Std. Error \\
\hline (Intercept) & $65.382^{* * *}$ & 3.397 \\
Experimental Condition Wolf Amish PAC & $8.030^{\wedge}$ & 4.230 \\
Liberal & $-14.821^{\star *}$ & 5.053 \\
Never interacts with Amish & -5.778 & 11.529 \\
Liberal: Never interacts with Amish & $-53.798^{* *}$ & 18.900 \\
\hline
\end{tabular}

$N=313$

Adj. R2: 0.08

$F(4,357)=9.122$, p. $<.001$

^p. $<.10 .{ }^{*}$ p. $<.05 .{ }^{* *}$ p. $<.01 .{ }^{* *} p<.001$.

\section{Figure 3}

Effect Plot of Predicted Amish Feeling Thermometer Scores by Ideology and Personal Exposure to Amish Liberal * No Amish Interaction

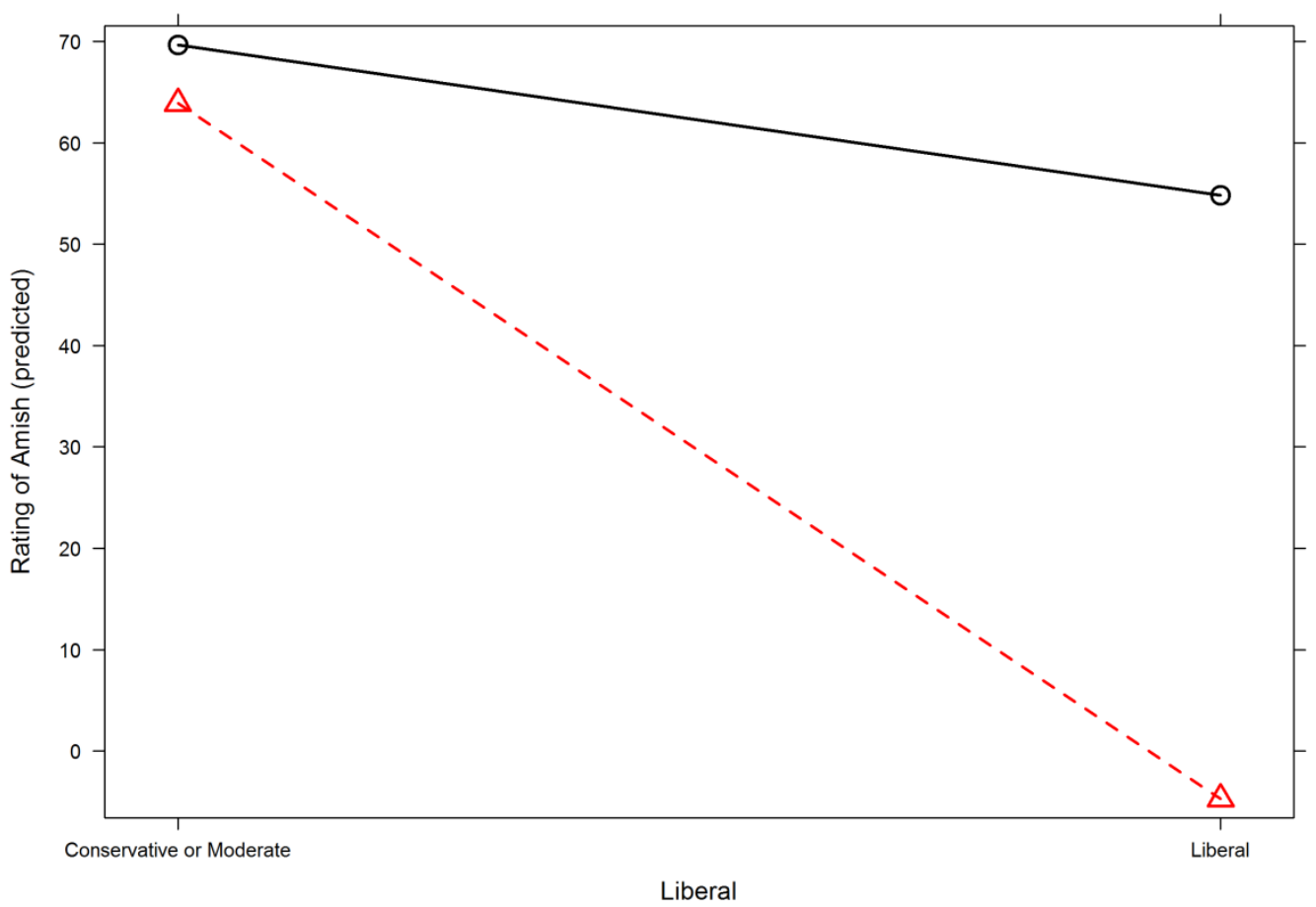




\section{Discussion}

These results provide further evidence of the increasing polarization evident in American society. While it is no surprise given the current climate that the image of a cultural group can be harmed when it is associated with specific political candidates and issues, it is concerning that a group's image is appropriated without its express consent and results in harm. Although Amish PAC's advertisements sought to influence potential Amish voters, the results presented here suggest that these advertisements affected non-Amish — not by influencing perceptions of a candidate, but instead by influencing perceptions of the group associated with the candidate.

This is obviously only a single study with a number of important limitations. One unknown is how the specific context and timing of the survey affected responses. The online survey was fielded in June of 2018, following the primary elections held in May. Tom Wolf, the incumbent governor, was unopposed in the primary, while Scott Wagner faced a bruising primary where he defeated challengers Paul Mango and Laura Ellsworth. The Mango campaign waged a fierce and particularly negative series of advertisements against Wagner, where, among other things, Wagner was depicted as a "slumlord," a bail bondsman who helped get a child abuser out of jail, and a "deadbeat dad" who didn't pay child support. The barrage of negative advertisements against Wagner was described by a veteran political scientist as the "most brutal" that he had observed in more than 30 years (Murphy, 2018). The intensity and quantity of the attacks coming from within Wagner's own party, and his relative unpopularity throughout the campaign, provides strong justification for lower feeling thermometer ratings among respondents exposed to the Wagner treatment.

It may be the case that respondents formed social identity groups based upon support for Wagner or Wolf, which influenced perceptions of the Amish. It is well-documented that divisions between social identity ingroups and outgroups have increased in recent years (see Mason, 2018). Given Wagner's relative unpopularity, it is possible that respondents perceived the Amish as part of an outgroup when they were associated with Wagner. This potential theoretical link to social identity merits further research.

The Amish PAC billboards deployed in 2016 supported Donald Trump, and he, too, was the subject of intense attacks. Furthermore, as a candidate, Scott Wagner modeled himself after Donald Trump, often emphasizing his roots as a business owner and even using the Twitter handle @realScottWagner (approximating Donald Trump's @ realDonaldTrump). While there were differences between the 2016 presidential campaign and the 2018 Pennsylvania gubernatorial campaign, there were important similarities in the Republican candidates (Baer, 2018). It is plausible that linking the Amish to Donald Trump resulted in similar evaluations of the Amish during the 2016 election.

Our results also highlight differences in how individuals perceive the Amish based upon the respondent's ideology and level of interaction with the Amish. We found that self-identified 
conservatives have the most favorable attitudes toward the Amish. ${ }^{7}$ Our results here also support the "contact hypothesis" (see Allport, 1954), and confirm McGuigan and Scholl's (2007) conclusion that increased contact with the Amish leads to more positive views of the group. In the context of a campaign, our results suggest that those individuals with little contact with a cultural group are more likely to have their partisan reaction influence their feeling about the group. This is another example of the power of party as a heuristic in the absence of other cues (Ciuk \& Yost, 2015).

For us, these findings raise fundamental questions about our current electioneering: What say does any group have in the way its image is deployed for political purposes? What criteria must be met before suggesting that a cultural group supports some cause or candidate? And if some group members do offer support, what rights, if any, should other group members have to constrain such claims? Could cultural appropriation constitute a disinformation campaign? If so, what are the ramifications?

There are no easy answers to these questions. But as campaign tactics and strategies continue to evolve, we may witness more instances of group appropriation for potential political gain. In that case, voters will pass judgment not only on a candidate, but also on the group that purportedly supports the candidate.

\section{References}

1001 questions and answers on the Christian life. (1992). Pathway Publishers.

Allport, G. W. (1954). The nature of prejudice. Addison-Wesley.

Baer, J. (2018, September). Scott Wagner's running a campaign like Trump's, but at least he's running a campaign. Philly.com. Retrieved October 1, 2020, from http://www.philly.com/philly/columnists/john_baer/scott-wagners-running-a-campaign-liketrumps-but-at-least-hes-running-a-campaign-20180923.html

Brader, T. (2005). Striking a responsive chord: How political ads motivate and persuade voters by appealing to emotions. American Journal of Political Science, 49(2), 388-405. https://doi.org/10.1111/j.0092-5853.2005.00130.x

Campbell, A., Converse, P. E., Miller, W. E., \& Stokes, D. E. (1960). The American voter. University of Chicago Press.

Ciuk, D., \& Yost, B. (2015). The effects of issue salience, elite influence, and policy content on public opinion. Political Communication, 33(2), 328-345.

https://doi.org/10.1080/10584609.2015.1017629

Edelman, M. (1964). The symbolic uses of politics. University of Illinois Press.

\footnotetext{
${ }^{7}$ This, too, suggests that Amish may have been viewed as a social ingroup by conservatives, perhaps due to a perception of shared policy preferences or values.
} 
Goren, P., \& Chapp, C. (2017). Moral power: How public opinion on culture war issues shapes partisan predispositions and religious orientations. American Political Science Review, 111(1), 110-128. https://doi.org/10.1017/S0003055416000435

Kopko, K. C. (2012). Religious identity and political participation in the Mennonite Church USA. Politics and Religion, 5(2), 367-393. https://doi.org/10.1017/S1755048312000077

Kraybill, D. B., \& Kopko, K. C. (2007). Bush fever: Amish and Old Order Mennonites in the 2004 presidential election. Mennonite Quarterly Review, 81(2), 165-205.

Kraybill, D. B., \& Nolt, S. M. (2004). Amish enterprise: From plows to profits (2nd ed.). Johns Hopkins University Press.

Mason, L. (2018). Uncivil agreement: How politics became our identity. University of Chicago Press. https://doi.org/10.7208/chicago/9780226524689.001.0001

McGuigan, W. M., \& Scholl, C. (2007). The effect of contact on attitudes toward Old Order Amish. Journal of Applied Social Psychology, 37(11), 2642-2659. https://doi.org/10.1111/j.1559-1816.2007.00274.x

Murphy, J. (2018, April). In increasingly nasty race, GOP governor candidate gets personal in new ad. PennLive. Retrieved October 1, 2020, from https://www.pennlive.com/politics/index.ssf/2018/04/pennsylvanias_gop_gubernatoria.html

Nelson, S. C. (2008). Feeling thermometer. In Lavrakas, P. J. (Ed.), Encyclopedia of survey research methods (pp. 275-277). SAGE.

Rahn, W. M. (1993). The role of partisan stereotypes in information processing about political candidates. American Journal of Political Science, 37(2), 472-496. https://doi.org/10.2307/2111381

Trollinger, S. L. (2012). Selling the Amish: The tourism of nostalgia. Johns Hopkins University Press.

Weaver-Zercher, D. L. (2001). The Amish in the American imagination. Johns Hopkins University Press.

Weaver-Zercher, V. (2013). Thrill of the chaste: The allure of Amish romance novels. Johns Hopkins University Press.

Zimmerman Umble, D., \& Weaver-Zercher, D. L. (Eds.). (2008). The Amish and the media. Johns Hopkins University Press. 


\section{Appendix A}

\section{Supplemental Information on the Creation of Amish PAC}

Amish PAC is a political action committee based in Arlington, Virginia. It was formed in 2016 by Benjamin Walters and Taylor Swindle, two Washington D.C.-area professionals with ties to PACs supporting Ben Carson and Newt Gingrich, respectively. Based upon interviews with Walters and Swindle, the origins of Amish PAC can be traced to Ben Carson's presidential campaign. The two noted that some members of the Amish community took interest in Carson's campaign because they were already familiar with Carson's books, which underscore his Christian faith. Some of Carson's books, like Gifted Hands: The Ben Carson Story, were sold in select Amish bookstores. When Walters worked for a PAC that supported Carson, he was contacted by an Amish publication seeking information on Carson's candidacy. That interaction, combined with Walters's personal familiarity with Amish and Mennonite civic engagement - his grandfather had been the mayor of Nappanee, Indiana - gave rise to the idea of mobilizing Amish voters in support of Republican candidates.

To facilitate interaction with the Amish community, Walters and Swindle sought to identify someone with connections to the Amish community in Lancaster County, Pennsylvania. They identified Benjamin King, a Ben Carson donor, as a potential contact based upon Federal Election Commission data. King was a former member of the Amish church and the owner of a construction firm in Lancaster County. After Walters and Swindle contacted King and met in person, the three worked collaboratively to identify the best ways of reaching Amish voters through advertisements for in-person meetings.

\section{Appendix B}

\section{Alternative Least-Squares Regression Models Specification and Effect Plot Predictions}

Table B1 presents the regression coefficients for the Amish feeling thermometer score and the full range of responses for the political ideology and Amish exposure variables. The regression results are consistent with the simplified model presented in Table 4, showing that feelings about the Amish are related to both political ideology and the interaction between ideology and personal exposure to the group. Figure B1 displays the interaction between ideology, personal exposure, and ratings. In this model, the adjusted ratings of the Amish were about 7.5 points higher among respondents who received the Wolf Amish PAC treatment than for those who received the Wagner Amish PAC treatment (p. $=.074)$. 


\section{Table B1}

Alternative Least-Squares Regression Predicting Feeling Towards Amish

\begin{tabular}{lrr}
\hline Variable & Estimate & Std. Error \\
\hline (Intercept) & $74.996^{* \star \star}$ & 17.693 \\
Experimental Condition Wolf Amish PAC & $7.509^{\wedge}$ & 4.193 \\
Liberal & $-83.751^{* * *}$ & 22.456 \\
Moderate & -24.687 & 22.452 \\
Rarely interacts with Amish & -16.492 & 18.645 \\
Sometimes interacts with Amish & 1.341 & 18.419 \\
Regularly interacts with Amish & 4.790 & 18.812 \\
Liberal: Rarely interacts with Amish & $68.208^{\star *}$ & 23.997 \\
Moderate: Rarely interacts with Amish & 14.267 & 23.906 \\
Liberal: Sometimes interacts with Amish & $62.708^{\star *}$ & 24.181 \\
Moderate: Sometimes interacts with Amish & 11.803 & 23.637 \\
Liberal: Regularly interacts with Amish & $76.859^{\star *}$ & 26.503 \\
Moderate: Regularly interacts with Amish & 24.240 & 25.089 \\
\hline
\end{tabular}

$\mathrm{N}=313$

Adj. $R^{2}: 0.13$

$F(12,357)=5.651$, p. $<.001$

^p. $<.10 .{ }^{*}$ p. $<.05 .{ }^{* *}$ p. $<.01 .{ }^{* * *}$ p $<.001$

\section{Figure B1}

Alternative Model Effect Plot of Predicted Amish Feeling Thermometer Scores by Ideology and Personal Exposure

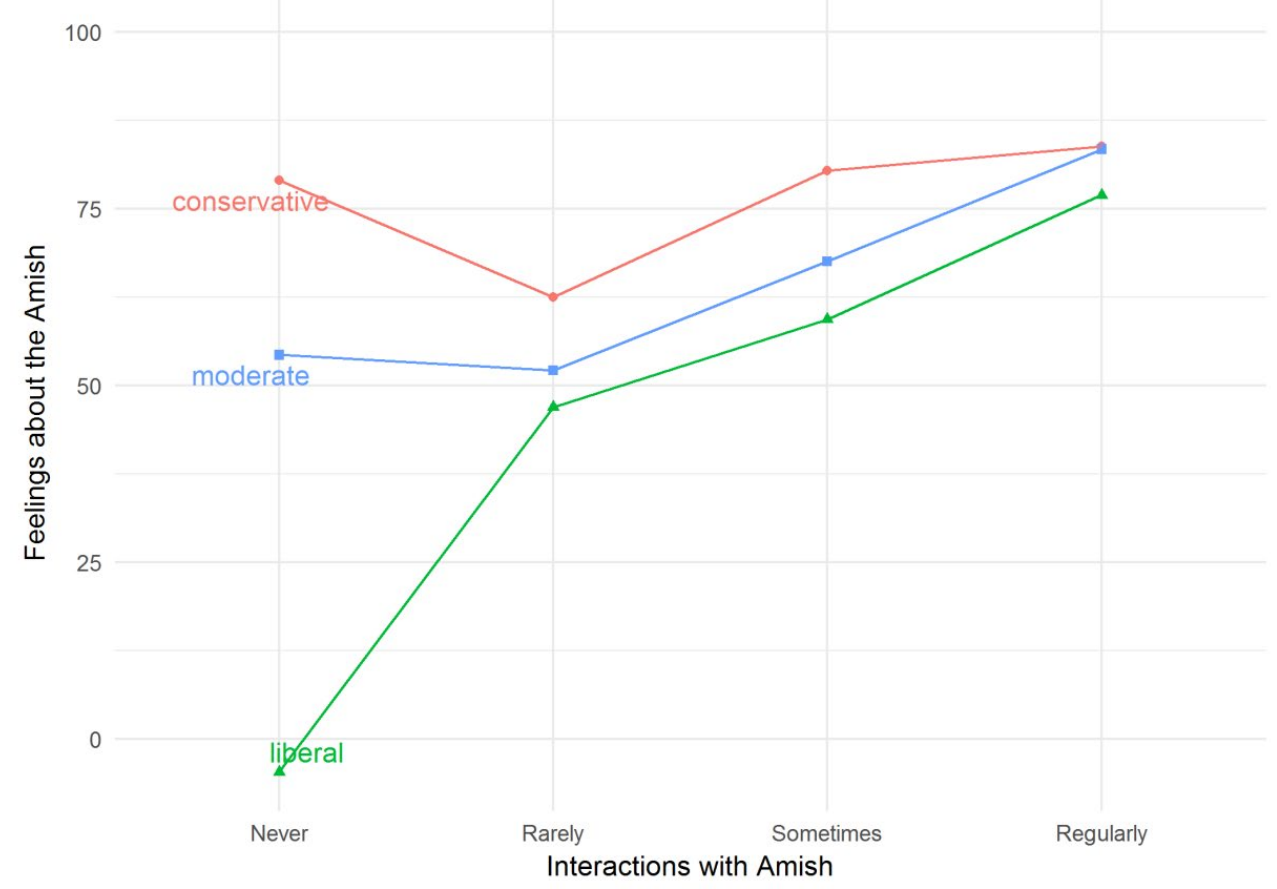

